\title{
Attentional switching forms a genetic link between attention problems and autistic traits in adults
}

\author{
T. J. C. Polderman ${ }^{1 *}$, R. A. Hoekstra ${ }^{2}$, A. A. E. Vinkhuyzen ${ }^{3}$, P. F. Sullivan ${ }^{4}$, S. van der Sluis ${ }^{1,5}$ \\ and D. Posthuma ${ }^{1,6,7}$ \\ ${ }^{1}$ Complex Trait Genetics, Department of Functional Genomics, Center for Neurogenomics and Cognitive Research (CNCR), Neuroscience Campus \\ Amsterdam (NCA), VU University Amsterdam, The Netherlands \\ ${ }^{2}$ Department of Life Sciences, Faculty of Science, The Open University, Milton Keynes, UK \\ ${ }^{3}$ The University of Queensland, Queensland Brain Institute, St Lucia, QLD, Australia \\ ${ }^{4}$ Department of Genetics, University of North Carolina at Chapel Hill, Chapel Hill, NC, USA \\ ${ }^{5}$ Functional Genomics Section, Department of Clinical Genetics, VU University Medical Centre, Amsterdam, The Netherlands \\ ${ }^{6}$ Medical Genomics Section, Department of Clinical Genetics, VU University Medical Centre, Amsterdam, The Netherlands \\ ${ }^{7}$ Department of Child and Adolescent Psychiatry/Psychology, Erasmus University Medical Center/Sophia Children's Hospital, Rotterdam, \\ The Netherlands
}

Background. Attention deficit hyperactivity disorder (ADHD) symptoms and autistic traits often occur together. The pattern and etiology of co-occurrence are largely unknown, particularly in adults. This study investigated the co-occurrence between both traits in detail, and subsequently examined the etiology of the co-occurrence, using two independent adult population samples.

Method. Data on ADHD traits (Inattention and Hyperactivity/Impulsivity) were collected in a population sample $(\mathrm{S} 1, n=559)$ of unrelated individuals. Data on Attention Problems (AP) were collected in a population-based family sample of twins and siblings (S2, $n=560$ ). In both samples five dimensions of autistic traits were assessed (social skills, routine, attentional switching, imagination, patterns).

Results. Hyperactive traits (S1) did not correlate substantially with the autistic trait dimensions. For Inattention (S1) and AP (S2), the correlations with the autistic trait dimensions were low, apart from a prominent correlation with the attentional switching scale ( 0.47 and 0.32 respectively). Analyses in the genetically informative S2 revealed that this association could be explained by a shared genetic factor.

Conclusions. Our findings suggest that the co-occurrence of ADHD traits and autistic traits in adults is not determined by problems with hyperactivity, social skills, imagination or routine preferences. Instead, the association between those traits is due primarily to shared attention-related problems (inattention and attentional switching capacity). As the etiology of this association is purely genetic, biological pathways involving attentional control could be a promising focus of future studies aimed at unraveling the genetic causes of these disorders.

Received 20 August 2012; Revised 9 November 2012; Accepted 13 November 2012; First published online 21 December 2012

Key words: ADHD, autism, co-morbidity, genetics, twin study.

\section{Introduction}

Attention deficit hyperactivity disorder (ADHD) and autism spectrum disorder (ASD) are two conditions that develop during childhood, but are also common conditions in adult psychiatric practice. ADHD is characterized by developmentally inappropriate levels of inattention, hyperactivity and impulsivity whereas ASD is characterized by impaired communication and

* Address for correspondence: T. J. C. Polderman, Ph.D., Complex Trait Genetics, Department of Functional Genomics, Center for Neurogenomics and Cognitive Research (CNCR), Neuroscience Campus Amsterdam (NCA), VU University Amsterdam, De Boelelaan 1085, 1081 HV, Amsterdam, The Netherlands.

(Email: tinca.polderman@vu.nl) social skills, repetitive behavior and restricted interests. About $4.5 \%$ of adults are diagnosed with ADHD (Simon et al. 2009), and the first prevalence study for ASD in adults suggests that about $1 \%$ of the population meet diagnostic criteria (Brugha et al. 2011). Of note, to be diagnosed as an adult for ADHD or ASD, part of the symptoms have to be recalled as having been present during childhood. ADHD and ASD often co-occur, with approximately $30-50 \%$ of adults diagnosed with ASD also meeting criteria for ADHD (Hofvander et al. 2009). Both conditions can have a large impact on the daily life of affected people and their families, which is aggravated when both conditions co-occur (Anckarsater et al. 2006). Yet little is known about the etiology of symptoms related to

The online version of this article is published within an Open Access environment subject to the conditions of the Creative Commons Attribution-NonCommercial-ShareAlike licence <http://creativecommons.org/licenses/by-nc-sa/3.0/ $>$. The written permission of Cambridge University Press must be obtained for commercial re-use. 
ADHD and ASD in adulthood and the pattern of co-occurrence.

The co-occurrence of psychiatric disorders may arise for several reasons (Neale \& Kendler, 1995; Riso et al. 1996; Cramer et al. 2010). For instance, the affection status of one disorder may increase the risk of developing a second disorder. Co-occurrence may also be due to chance, when two disorders are autonomous, independent disorders. Alternatively, co-occurrence may arise because of a shared etiological factor. Given the very early and often parallel onset of both ADHD and ASD, and the fact that comorbidity is much higher than would be expected based on the prevalence of each disorder (i.e. 30-50\% of adult patients with ASD show ADHD symptoms, and vice versa) (Stahlberg et al. 2004; Anckarsater et al. 2006; Hofvander et al. 2009), we assume that a shared etiological factor is most likely.

Because of the early onset of both disorders, etiological research into ADHD and ASD has focused mainly on children, and most studies have been conducted in population-based twin and family samples. Population-based studies are, next to clinical studies, a useful design for examining disorder characteristics. The underlying symptoms related to ADHD and ASD show a dimensional distribution in the general population (Constantino \& Todd, 2003; Polderman et al. 2007), enabling the use of trait measures and as such providing more power for quantitative genetic analyses than case-control designs. Moreover, the etiology of the conditions has been shown to be similar in the extreme end and in the normal variation of both ASD (Robinson et al. 2011; Lundstrom et al. 2012) and ADHD (Larsson et al. 2012). Heritability estimates of around $75 \%$ for both traits suggest that genetic factors play an important role in the etiology of both ADHD(Nikolas \& Burt, 2010) and ASD-related traits (Ronald \& Hoekstra, 2011) during childhood, and that environmental factors play a more modest role. Few studies have investigated the etiological factors of ADHD and ASD traits in adult samples. Heritability estimates of around $35 \%$ have been observed for ADHD symptoms (van den Berg et al. 2006; Boomsma et al. 2010), and Hoekstra et al. (2007) reported a heritability of $57 \%$ for autistic traits in a sample of 18-year-old twins. Thus, these studies suggest that genetic factors continue to play a role in ADHD- and ASD-related traits in adulthood, but to a smaller extent than during childhood (for a review on heritability change over time in ADHD, see Franke et al. 2012).

The shared etiology of ADHD and ASD traits in children was investigated in three (non-clinical) twin studies, showing an increasing genetic correlation $\left(r_{\mathrm{g}}\right)$ between ADHD and ASD traits with age. A study in 312 2-year-old twin pairs in the USA reported a genetic correlation of 0.27 (Ronald et al. 2010). In a much larger sample of 8- to 9-year-old twins $(n=6771)$ in UK families, a genetic correlation of 0.55 was found (Ronald et al. 2008). Lastly, Lichtenstein et al. (2010) observed a genetic correlation of 0.87 in a very large sample (>10000) of 9- to 12-year-old Swedish twins. These findings indicate that genetic factors, common to both traits, play an important role in the cooccurrence of ADHD and ASD traits in children. The increasing genetic correlation with age suggests that the genetic overlap may become stronger in more advanced stages of child development, although these findings should be interpreted with caution as they all derive from cross-sectional rather than longitudinal studies, using different samples and different instruments to assess ADHD and ASD traits.

Two twin studies have investigated the etiology of the co-occurrence of ADHD and autistic traits in adults. Reiersen et al. (2008) measured autistic traits with 11 items of the Social Responsiveness Scale (SRS) and ADHD traits with 12 items of DSM-IV $(n=674$ participants, mean age 23 years). The SRS and ADHD scores were significantly correlated on a phenotypic $\left(r_{\mathrm{p}}=0.48\right)$ and genetic level $\left(r_{\mathrm{a}}=0.72\right)$. More recently, Lundstrom et al. (2011) investigated the phenotypic and genetic association between autistic traits and ADHD traits (both trait measures based on DSM-IV items) in a nationwide sample of 18349 adults (age range 20-47 years). They observed a phenotypic correlation of 0.44 and a genetic correlation of 0.53 .

In sum, research on ADHD and ASD in adults is very sparse, and therefore understanding the etiology of ASD and ADHD traits and their co-occurrence in adulthood is, as yet, poor. The current study aimed to fill this gap by investigating the co-occurrence of ADHD traits and autistic traits, and their shared etiology, in detail. Whereas previous studies focused on the association between simple composite measures of ADHD and ASD, we aimed to investigate this association in depth by focusing on dimensional measures of the components of ADHD and ASD. Such analyses could enhance our understanding of the co-morbidity patterns as seen in clinical practice, and help to identify shared genetic underpinnings.

To this end, we used five autistic traits that are related to known behavioral or cognitive characteristics of ASD: (1) social skills impairment, (2) a strong routine preference, (3) difficulties with attentional switching, (4) imagination impairments, and (5) a fascination for numbers and patterns. In addition, we distinguished traits of subtypes of ADHD as used in DSM-IV (i.e. Hyperactive/Impulsive and Inattentive subtype and Combined subtype) in one sample, and focused on Attention Problems (AP) in a second, independent sample. The aim of this study was 
twofold: first, to examine in detail the phenotypic association of autistic traits with ADHD traits and AP in two independent adult general population samples; and second, to investigate the genetic and environmental etiology of the co-occurrence of autistic traits and AP.

\section{Method \\ Sample}

Participants volunteered in the Netherlands Study of Cognition, Environment and Genes (NESCOG), which comprises a general population sample (sample 1) and a genetically informative, family-based sample (sample 2). The aim of NESCOG is to study individual differences in cognition and cognitive-related disorders. Sample 1 (S1, $n=837$ ) was recruited through media advertisement or through the Science Live Program of the NEMO Science Center in Amsterdam (www.sciencelive.nl). Apart from cognitive tasks, participants were asked to complete an online behavioral questionnaire concerning life events, personality, environmental factors and behavioural conditions, which included ADHD traits and autistic traits. At the time of writing, the questionnaire had been completed by 559 subjects (67\%, mean age 41.51 years, S.D. $=11.29$, range $17-78$ years), of whom $371(66 \%)$ were females. Four parent-offspring and around 140 spousal relationships were present in this sample. Following categorization of educational attainment used previously in Dutch studies (van der Sluis et al. 2008), the distribution of education was as follows: primary school only, $0.5 \%$; lower vocational school and lower secondary school, 6.6\%; intermediate vocational school and intermediate or higher secondary school, 32.9\%; higher vocational school and university, $59.9 \%$.

Sample 2 (S2, $n=560 ; 330$ females) was a general population-based family sample that had participated in a study on the genetics of cognition and the interplay with life events (Vinkhuyzen et al. 2010). The mean age in this sample was 46.58 years (s.D. $=12.40$, range 23-75 years). All participants completed a behavioral questionnaire (slightly different from that completed by S1) about life events, environmental factors and behavioral conditions, including items on AP and autistic traits. We used data from twins [150 complete twin pairs, of which 82 were monozygotic (MZ), 68 dizygotic (DZ) and 87 incomplete twin pairs (28 MZ)], one triplet and all full siblings $(n=172)$. Zygosity of same-sex twin pairs was based on survey questions about physical similarity and confusion of twins by family members and strangers, or on DNA polymorphisms (97 pairs). For more details on S2, see Vinkhuyzen et al. (2010).
The Central Committee on Research Involving Human Subjects in The Netherlands provided institutional review board (IRB) approval for both NESCOG samples in this study. After complete description of the study to the subjects, written informed consent was obtained.

\section{Measures \\ ADHD traits}

In S1, ADHD traits were measured with the selfreported Conners' Adult ADHD Rating Scales (CAARS). Thirty items were rated on a four-point scale $(1=$ never, $2=$ sometimes, $3=$ often, and $4=$ very often) regarding behavior in the past months. Four subscales can be derived: Inattention (CAARS-I, nine items), Hyperactivity/Impulsivity (CAARS-HI, nine items), ADHD total (sum of Inattention and Hyperactivity/Impulsivity items) and ADHD index (CAARS index, 12 items). The ADHD index differs from the ADHD total in that it specifically identifies subjects who are likely to have an ADHD diagnosis according to DSM-IV criteria (Conners et al. 1999). The CAARS-I and CAARS-HI scales were analysed to investigate the relationship between specific dimensions of ADHD traits and autistic traits. To examine the relationship between a potential ADHD diagnosis and autistic traits, we also incorporated the CAARS index scale.

\section{$A P$}

Participants in S2 completed the AP scale of the Young Adult Self-Report (YASR; Achenbach, 1997). The YASR-AP scale consists of seven items that mainly focus on inattentive symptoms. It is rated on a threepoint scale $(1=$ never, $2=$ sometimes and $3=$ often $)$ regarding behavior in the past 6 months.

\section{Autistic traits}

In both samples, autistic traits were measured with the abridged version of the self-report Autism-Spectrum Quotient (AQ; Baron-Cohen et al. 2001). The abridged version (AQ-Short) comprises 28 items rated on a four-point scale ( 1 =definitely agree, $2=$ slightly agree, $3=$ slightly disagree, and $4=$ definitely disagree). If applicable, items are scored reversely such that a higher score refers to more autistic problems. High scores on the AQ-Short have been shown to be indicative for ASD in Dutch and in UK populations (Hoekstra et al. 2011). Along with a total score (AQ-Short Total), five subscales can be derived from the AQ-Short, namely Social Skills (AQ-Short Social; seven items), Routine (AQ-Short Routine; four items), 
Attentional Switching (AQ-Short Switch; four items), Imagination (AQ-Short Imagination; eight items), and Numbers and Patterns (AQ-Short Numbers; five items).

\section{Test-retest reliability}

Out of a small independent population sample, comprising 37 parent-offspring pairs, 60 participants completed the behavioral questionnaire of S2 twice in 2 months. These data were used to examine the test-retest reliability of the AQ-Short scales and the YASR-AP scale. Written consent was obtained from each participant.

\section{Statistical analyses}

To accommodate familial or spousal dependencies in S1, S2 and the test-retest sample, all analyses were conducted with structural equation modeling in $\mathrm{Mx}$ (Neale et al. 2006). Mx provides parameter estimates by maximizing the raw data likelihood. Estimates of means, variances and phenotypic correlations were obtained from a saturated model in which the phenotypic variance was not decomposed into genetic or environmental factors. Additionally, in S2, correlations were estimated for each measure between twins (intra-pair MZ and DZ twin correlations) and between twins and siblings (twin-sibling correlations). By constraining DZ twin correlations to be equal to twin-sibling correlations, we could test whether they differed significantly. Within-subject correlations between phenotypes $\left(r_{\mathrm{p}}\right)$ were constrained to be equal across zygosity and all family members. In both S1 and S2 we tested whether the covariates of sex and age had a significant effect on the means. The applied model was $\mu=\alpha+\beta_{1}$ sex $+\beta_{2}$ age, where $\beta$ values were based on raw data, sex was coded 0 for males and 1 for females, and age was given as actual age in years.

Specific hypotheses (e.g. $r_{\mathrm{p}}$ deviates significantly from zero) were evaluated using hierarchical likelihood ratio $\left(\chi^{2}\right)$ tests. The $\chi^{2}$ statistic is computed by taking twice the difference between the log-likelihood of a reference model and the log-likelihood of a submodel with certain constraints, and the associated degrees of freedom are computed as the difference in degrees of freedom between the two models (Rijsdijk, 2007).

\section{Twin-sibling design}

Information on MZ and DZ twins and non-twin siblings was used to decompose the observed variance of a particular trait, and also the covariance between traits, into latent genetic and environmental variance components. These components are additive genetic influences (A, additive effects of genes at multiple loci), dominant genetic influences $(D$, interaction of genetic effects at the same loci), environmental influences that are shared among family members ( $C$, common, shared environmental effects), and environmental influences that are unique for a person (E). Because MZ twins are genetically identical, they share all their additive and dominant genetic effects. DZ twins and normal siblings share, on average, half of their segregating genes and therefore, on average, half of their additive genetic effects and a quarter of their dominant genetic effects. All twins and siblings in this sample grew up in the same family and thus share their family environment.

\section{Genetic models}

The choice of an AE, ACE or ADE model is usually based on the MZ correlations and DZ/twin-sibling correlations. $\mathrm{MZ}$ correlations twice as high as DZ/ twin-sibling correlations indicate the presence of additive genetic influences (AE), whereas DZ/twinsibling correlations lower than half the MZ correlations indicate the presence of dominant genetic influences (ADE; as dominant genetic effects can only exist in the presence of additive genetic effects, A and $\mathrm{D}$ are necessarily both included in the models). DZ/twin-sibling correlations higher than half the MZ correlations indicate potential shared environmental influences (ACE), and MZ correlations that are of similar magnitude to $\mathrm{DZ} /$ twin-sibling correlations indicate that only environmental influences play a role (CE). The unique environmental component (E) includes measurement error and is therefore always included in the models. Because common environmental effects $(C)$ make family members more similar whereas dominant genetic effects (D) reduce the expected phenotypic resemblance in DZ twins and siblings relative to $M Z$ twins, the effects of $C$ and $D$ cannot be estimated simultaneously in the twin model (Boomsma et al. 2002).

The genetic or environmental variance explained is usually reported in a standardized form, as a proportion, by dividing this part of the variance by the total phenotypic variance. The proportion of variance that is explained by genetic effects (A and D) is called the broad-sense heritability estimate (i.e. heritability is calculated as genetic variance divided by the total phenotypic variance). As the power to detect sex differences on the variance and covariance components was expected to be low (Polderman et al. 2006), we combined male and female data. This choice seems justified as there is no evidence that sex moderates co-morbidity patterns in ADHD (Biederman et al. 2004), or that sex influences variance/covariance 
Table 1. Estimated means, standard deviations (S.D.), significant sex and age effects for the AQ-Short scales, CAARS ADHD symptom scales (S1) and YASR Attention Problems (AP) scale (S2)

\begin{tabular}{|c|c|c|c|c|}
\hline & \multicolumn{2}{|l|}{$\mathrm{S} 1(n=559)$} & \multicolumn{2}{|l|}{ S2 $(n=558)$} \\
\hline & Mean (S.D.) & $\beta$ sex $/ \beta$ age & Mean (S.D.) & $\beta$ sex $/ \beta$ age \\
\hline AQ-Short Total & $55.67(9.55)$ & $-2.86 / 0.09$ & $53.59(8.46)$ & $-2.46 / 0.08$ \\
\hline AQ-Short Social & $12.65(3.82)$ & $-/ 0.03$ & $12.96(3.22)$ & $-/-$ \\
\hline AQ-Short Routine & $8.05(2.26)$ & $-/-$ & $7.97(2.07)$ & $-/-$ \\
\hline AQ-Short Switch & $9.26(2.37)$ & $-0.59 /-$ & $7.52(2.09)$ & $-0.31 / 0.03$ \\
\hline AQ-Short Imagination & $13.97(3.63)$ & $-/ 0.06$ & $14.88(3.58)$ & $-/ 0.05$ \\
\hline AQ-Short Numbers & $11.67(3.61)$ & $-1.79 /-$ & $10.20(3.08)$ & $-1.66 /-$ \\
\hline Inattentive & $6.89(3.44)$ & $-/-$ & & \\
\hline Hyper/Impulsive & $9.31(3.46)$ & $-/ 0.03$ & & \\
\hline ADHD index & $10.29(4.14)$ & $0.74 /-$ & & \\
\hline Attention Problems & & & $9.95(1.85)$ & $-/-$ \\
\hline
\end{tabular}

AQ-Short, Abridged version of the Autism-Spectrum Quotient; CAARS, Conners' Adult ADHD Rating Scales; ADHD, attention deficit hyperactivity disorder; YASR, Young Adult Self-Report.

The applied model is $\mu=\alpha+\beta_{1}$ sex $+\beta_{2}$ age, where $\beta$ values are based on raw data, sex is coded 0 for males and 1 for females, and age is given as actual age in years.

Table 2. Estimated phenotypic correlations of the AQ-Short scales with the CAARS ADHD symptom scales in S1 and the YASR Attention Problems (AP) scale in S2

\begin{tabular}{lllll}
\hline & \multicolumn{2}{c}{ S1 $(n=559)$} & & \\
\cline { 2 - 4 } & Inattentive & Hyperactive/Impulsive & ADHD index & $\begin{array}{l}\text { S2 }(n=558) \\
\text { AP }\end{array}$ \\
\hline AQ-Short Total & $0.20^{\mathrm{a}}$ & -0.01 & $0.30^{\mathrm{a}}$ & $0.16^{\mathrm{a}}$ \\
AQ-Short Social & 0.10 & -0.12 & $0.20^{\mathrm{a}}$ & 0.08 \\
AQ-Short Routine & 0.09 & -0.01 & $0.20^{\mathrm{a}}$ & $0.14^{\mathrm{a}}$ \\
AQ-Short Switch & $0.47^{\mathrm{a}}$ & -0.02 & $0.36^{\mathrm{a}}$ & $0.32^{\mathrm{a}}$ \\
AQ-Short Imagination & 0.10 & -0.05 & 0.09 & 0.01 \\
AQ-Short Numbers & -0.03 & $0.17^{\mathrm{a}}$ & $0.14^{\mathrm{a}}$ & 0.05 \\
\hline
\end{tabular}

AQ-Short, Abridged version of the Autism-Spectrum Quotient; CAARS, Conners' Adult ADHD Rating Scales; ADHD, attention deficit hyperactivity disorder; YASR, Young Adult Self-Report.

a Significant at $p<0.01$; all correlations were based on means corrected for sex and age effects where appropriate.

decomposition of ADHD and ASD traits in adults (Reiersen et al. 2008).

\section{Results}

In S2, two clear outliers (both males) with scores $>3$ standard deviations (s.D.) from the mean for the AQ-Short total scale and the AP scale were removed. Test-retest correlations were 0.68 for the AP scale, 0.83 for AQ-Short Total, 0.80 for AQ-Short Social, 0.65 for AQ-Short Routine, 0.66 for AQ-Short Switch, 0.75 for AQ-Short Imagination and 0.88 for AQ-Short Numbers. Test-retest measures were only conducted for the S2 questionnaire data. We have no data on the reliability of the CAARS measures in S1.
However, a previous study reported a 6-month test-retest correlation of 0.67 for the CAARS index (Boomsma et al. 2010). Values of Cronbach's $\alpha$ for the measured scales in S1 and S2 were acceptable (0.62-0.78 and 0.50-0.77 respectively), given the low number of items for some of the scales (Cortina, 1993). Table 1 shows descriptive statistics for all measures in S1 and S2, including significant sex and age effects on the mean. Significant effects only were included in the subsequent analyses. The means of S1 and S2 on the AQ scales were not significantly different, except for the AQ-Short Switch scale (fit statistics not shown).

Table 2 presents phenotypic correlations of the CAARS scales and the AP scale with the AQ-Short 


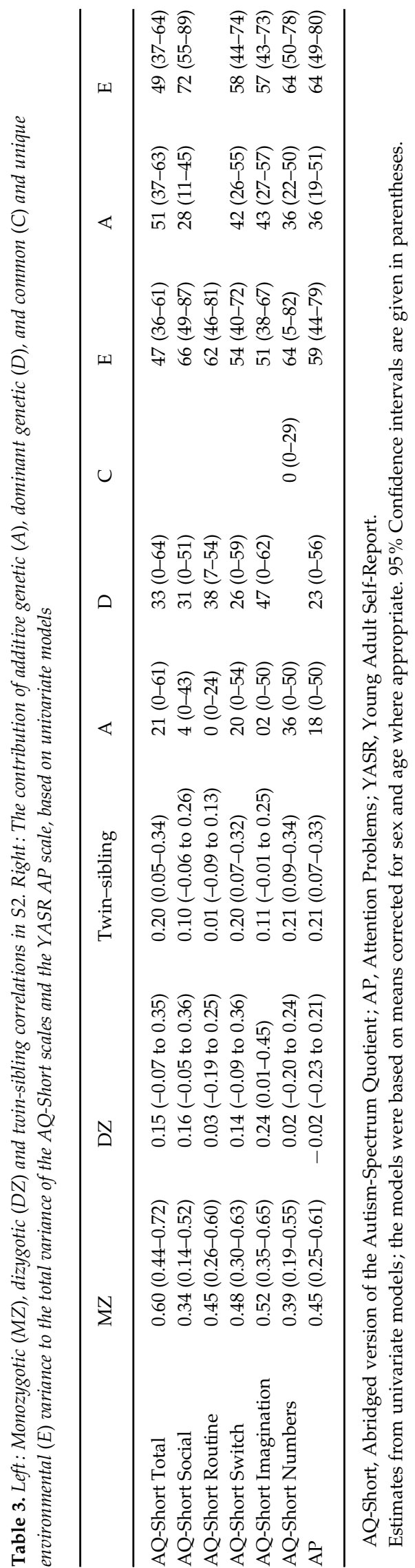

scales. In S1, most correlations between CAARS-HI and the AQ-Short scales were non-significant or low, two correlations were significant for CAARS-I and almost all correlations were significant for the CAARS index scale. Most prominent was the correlation between the AQ-Short Switch scale and both the CAARS-I and CAARS index scale $(r=0.47$ and 0.36 respectively). This finding was replicated in S2, where the AP scale correlated most prominently with the AQ-Short Switch scale $(r=0.32)$.

\section{Genetic results}

Table 3 gives the twin correlations and standardized estimates of additive and dominant genetic effects, and common and unique environmental effects, based on univariate models. DZ twin correlations were not significantly different from twin-sibling correlations on any of the scales. Overall, $\mathrm{MZ}$ twin correlations were higher than $\mathrm{DZ} /$ twin-sibling correlations indicating genetic influences. As the equated DZ/ twin-sibling correlations were lower than half the MZ correlation, we allowed for dominant genetic effects by fitting an ADE model, except for AQ-Short Numbers, where an ACE model was applied. We tested whether $C$ or D could be eliminated from the models (Table $4 a$ ). The most parsimonious model for all scales was a model with A and E, apart from AQ-Short Routine. Broad heritability estimates ranged between $28 \%$ and $51 \%$.

For AQ-Short scales that were significantly correlated with the AP scale in S2, we investigated whether the covariance between scales was best explained by additive genetic or unique environmental factors (i.e. AQ-Short Total, Switch and Routine). MZ cross-trait/ cross-twin correlations were higher than DZ/twinsibling cross-trait correlations on all three scales, with respectively $0.20,0.34$ and 0.10 for $\mathrm{MZ}$ twins and 0.04 , 0.12 and 0.01 for DZ/twin-siblings. Table $4 b$ shows the fit statistics of a series of bivariate genetic models that we subsequently tested for each AQ scale. Dropping D from the models gave no significant worsening of model fits. Subsequent tests showed that, for AP and AQ-Short Total, covariance due to genetic factors could not be eliminated whereas dropping the covariance due to unique environmental factors did not worsen the model fit. Genetic factors explained all of the phenotypic correlation between these scales. The genetic correlation of 0.40 suggested that partly overlapping genetic factors play a role in the AP score and the overall autistic traits score. For the AP and AQ-Short Routine scale, the pattern was less clear as either covariance due to genetic, or unique environmental factors could be deleted from the model, whereas deleting both was not allowed. 
Table 4. Model-fitting results of (a) univariate genetic models for the AQ-Short scales and the YASR AP scale and (b) bivariate genetic models for the AQ-Short Total, AQ-Short Routine and AQ-Short Switch scale with the YASR AP scale

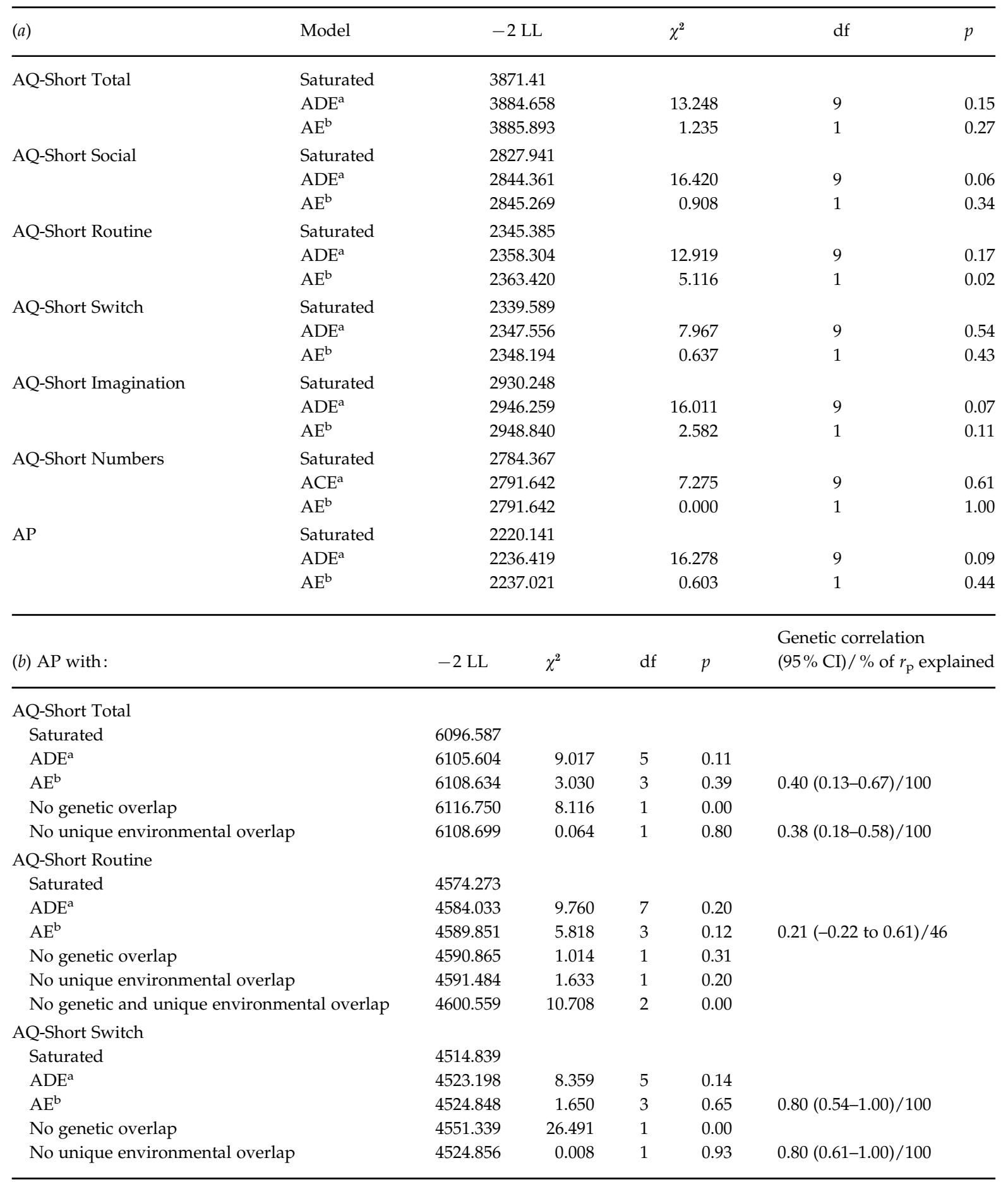

AQ-Short, Abridged version of the Autism-Spectrum Quotient; YASR, Young Adult Self-Report; LL, log likelihood; df, degrees of freedom; CI, confidence interval; AP, Attention Problems.

${ }^{\text {a }}$ Compared to saturated model.

${ }^{\mathrm{b}}$ Compared to ADE model.

Finally, for AP and the AQ-Short Switch scale, the covariance was explained fully by genetic factors. A genetic correlation of 0.80 suggested that a set of overlapping genes has an influence on the AP score and also on the AQ-Short Switch score (for path loadings, see Fig. 1). 

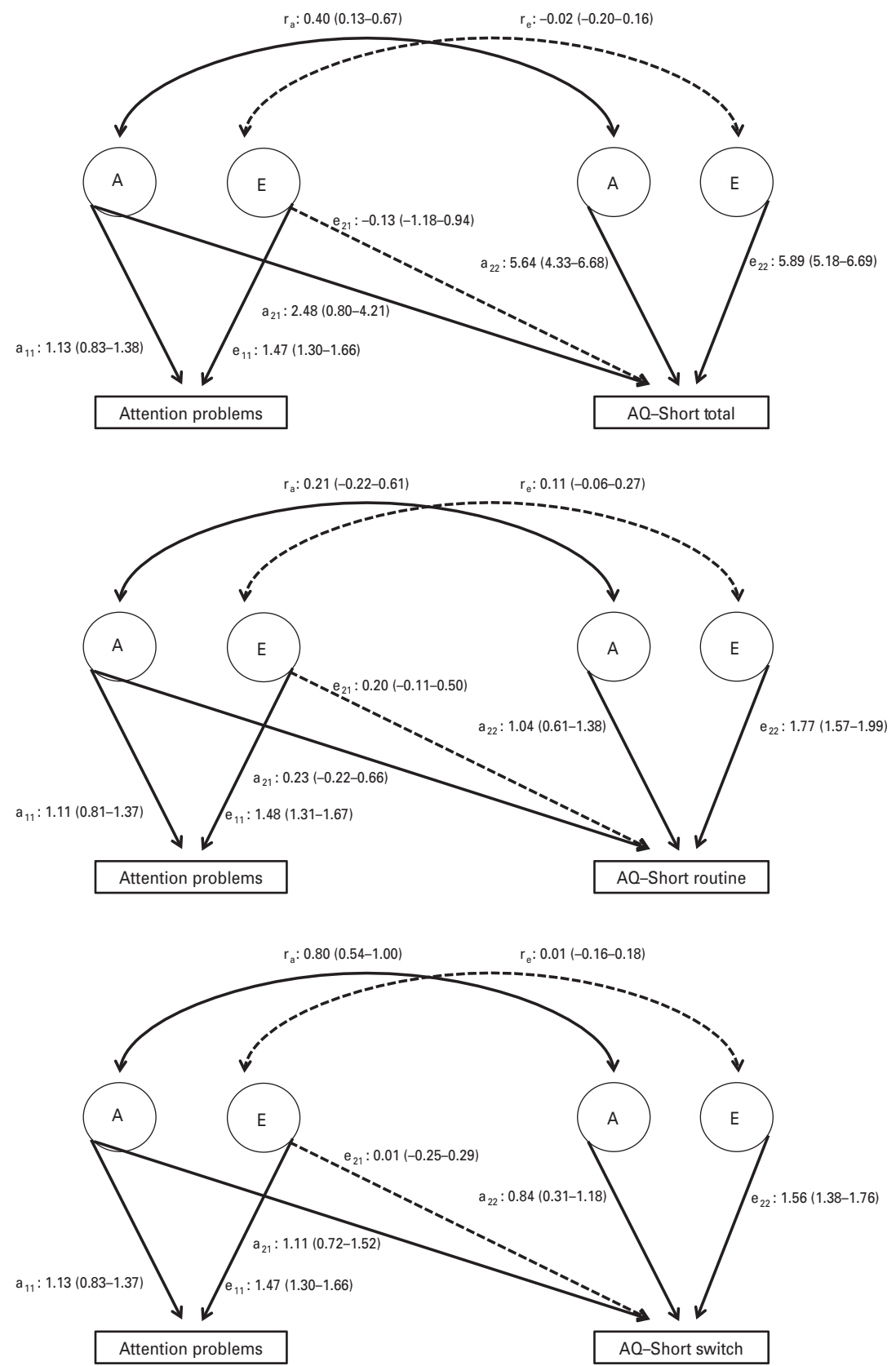

Fig. 1. Final (AE) model of Attention Problems (AP) and the abridged version of the Autism-Spectrum Quotient (AQ-Short) scales for one individual with unstandardized path loadings, genetic $\left(r_{\mathrm{a}}\right)$ and unique environmental $\left(r_{\mathrm{e}}\right)$ correlation, including confidence intervals. A, latent additive genetic factor; $\mathrm{E}$, latent unique environmental factor. Dashed lines indicate non-significant path loading.

Heritability $\mathrm{AP}=\frac{a_{11}^{2}}{a_{11}^{2}+e_{11}^{2}}$

Heritability AQ-Short Scale $=\frac{a_{21}^{2}+a_{22}^{2}}{a_{21}^{2}+a_{22}^{2}+e_{21}^{2}+e_{22}^{2}}$,

Genetic correlation between AP and AQ-Short Scale $=\frac{a_{11} \times a_{21}}{\sqrt{a_{11}^{2}} \times \sqrt{a_{21}^{2}+a_{22}^{2}}}$.

\section{Discussion}

This is the first study to examine the (genetic) relationship between specific characteristics of ADHD and autistic traits in adults. The strength of our study is that we report remarkably similar phenotypic findings in two independent samples with two different measures of ADHD traits/AP: first, an apparent 
association between inattentive traits of ADHD and the attentional switching dimension of autistic traits; and second, a low to moderate association with the remaining autistic trait dimensions. We strengthen our findings with genetic analyses in one of the samples (S2) with a twin-sibling design. Upon the clear phenotypic association, an important genetic overlap between attentional switching and AP was observed. Our findings fit well in the 'fractionable triad hypothesis' proposed by Happe \& Ronald (2008), which states that largely independent genes operate on different characteristics of autism. Following that reasoning we would expect that the shared genetic etiology between AP and autistic traits is most evident in specific autistic characteristics rather than the whole autistic spectrum. Indeed, our study suggests that the ability to switch attention specifically represents this shared genetic etiology.

Our results are not completely in line with the study by Reiersen et al. (2008), who reported a phenotypic correlation of 0.47 and a genetic correlation of 0.72 between ADHD traits representing mainly inattention (which fits with our results) and autistic traits mainly referring to reciprocal social behavior and, to a lesser extent, repetitive behaviors. The latter deviates from our findings, as social skills and routine were only modestly associated with inattentive behavior in our samples. The sample in the study of Reiersen et al. (2008) was comparable to those in the current study except that the age was much lower than in the current samples (mean age of 23 years $v .41 / 46$ years); this might explain the difference in results.

In sum, this study suggests that the co-occurrence of ADHD symptoms and ASD traits is not driven by behavioral impairments such as hyperactivity, social skills, imagination or routine preferences but to shared problems on an attentional level. Our findings did not result from an overlap in AQ-Short Attentional Switching items and the Inattention items of the CAARS (S1, e.g. 'I cannot concentrate when at work', 'I have trouble finishing tasks') or the items of the AP scale (S2, e.g. 'I daydream a lot', 'I cannot focus my attention'). The AQ-Short Attentional Switching scale refers specifically to 'the ability to easily switch attention', 'perform simultaneously multiple tasks' or 'follow multiple conversations', daily skills that need concentration and cognitive flexibility. Recently, Kessler et al. (2010) showed that similar deficits in executive functioning (defined by the authors as daily life self-regulation, such as 'the ability to organize, prioritize and integrate cognitive functions') were the most discriminating predictors of adult ADHD. They suggested that a working memory deficit could underlie these symptoms. Attentional switching and working memory largely depend on prefrontal processing (Diamond, 2011), which in turn is modulated by dopaminergic systems (Cools \& D'Esposito, 2011), which have previously been associated with ADHD (Franke et al. 2012). Executive functioning deficits, related to cognitive flexibility, have been reported for ASD and ADHD in children; however, findings were not always consistent (for an overview, see Rommelse et al. 2011).

A general finding from recent genetic studies of complex traits such as ASD and ADHD is polygenicity (Visscher et al. 2012). Common types of complex traits are associated with genetic variation at hundreds of loci. Therefore, it would not be expected that a few genes account for the variation in ADHD and ASD, or for the co-morbidity between them. Recent genomewide association studies (GWAS) on autism (Anney et al. 2010) and ADHD (Neale et al. 2010) have not revealed any genome-wide significant hits, probably because the sample sizes were too small. An increasing number of clinical studies have reported on rare variants associated with ADHD (Williams et al. 2010; Elia et al. 2011) and ASD (Pinto et al. 2010; Levy et al. 2011), of which some were overlapping (Taurines et al. 2012; Williams et al. 2012). However, it is difficult to interpret the functional implications of these results. Many identified mutations are in non-coding regions of the genome, others are involved in a variety of cellular processes (e.g. signaling pathways, protein interaction networks), and no clear pattern can yet be discerned. Our results suggest that biological pathways related to attentional control might be involved in specific co-morbidity patterns of ADHD and ASD in adults. Hence, attentional control might be a useful (endo)phenotype in future genetic studies.

The following methodological considerations warrant discussion. First, our measures were based only on self-reports. With multiple informants, situational variation in behavior can be taken into account, and in twin analyses potential sibling interaction issues can be examined. It has also been suggested that self-ratings produce lower heritability estimates (see Franke et al. 2012); indeed, the heritability estimates as presented in the current study are lower than those in children, where usually parental or teacher ratings are used. Second, the family sample was underpowered to detect genetic dominance effects (Posthuma \& Boomsma, 2000). However, using a very large sample, Boomsma et al. (2010) showed recently that ADHD trait variance is best explained with the model we applied to our data. Third, it is important to note that this study was performed in non-clinical population-based samples; the picture may be different in clinical populations. The ADHD index scale used in S1 is indicative of an ADHD diagnosis, and indeed showed somewhat higher correlations with the AQ-Short 
scales compared to the other scales. It would be of interest to examine the association between ADHD symptoms and similar autism measures in clinical (preferably family) samples.

To summarize, our results suggest that ADHD traits and autistic traits in adults are associated as a result of attention-related problems. As the nature of this association is purely genetic, biological pathways involving attentional control might be the focus of future studies aimed at finding genes for ASD and ADHD.

\section{Acknowledgments}

We thank all participating subjects. This research was part of Science Live, the innovative research program of science center NEMO that enables scientists to carry out peer-reviewed research using NEMO visitors as volunteers. Collaboration between P.F.S. and the CNCR was facilitated by the Royal Academy of Arts and Sciences of The Netherlands, Visiting Professor Program (ISK/5913/VPP). The Netherlands Organization for Scientific Research (NWO) Division for the Social Sciences (MaGW) provided funding for this research through grant VENI-451-08-025 to S.vdS. and VIDI 016-065-318 to D.P.

\section{Declaration of Interest}

None.

\section{References}

Achenbach TM (1997). Manual for the Young Adult Self-Report and Young Adult Behavior Checklist. Department of Psychiatry, University of Vermont: Burlington, VT.

Anckarsater H, Stahlberg O, Larson T, Hakansson C, Jutblad SB, Niklasson L, Nyden A, Wentz E, Westergren S, Cloninger CR, Gillberg C, Rastam M (2006). The impact of ADHD and autism spectrum disorders on temperament, character, and personality development. American Journal of Psychiatry 163, 1239-1244.

Anney R, Klei L, Pinto D, Regan R, Conroy J, Magalhaes TR, Correia C, Abrahams BS, Sykes N, Pagnamenta AT, Almeida J, Bacchelli E, Bailey AJ, Baird G, Battaglia A, Berney T, Bolshakova N, Bolte S, Bolton PF, Bourgeron T, Brennan S, Brian J, Carson AR, Casallo G, Casey J, Chu SH, Cochrane L, Corsello C, Crawford EL, Crossett A, Dawson G, de Jonge M, Delorme R, Drmic I, Duketis E, Duque F, Estes A, Farrar P, Fernandez BA, Folstein SE, Fombonne E, Freitag CM, Gilbert J, Gillberg C, Glessner JT, Goldberg J, Green J, Guter SJ, Hakonarson H, Heron EA, Hill M, Holt R, Howe JL, Hughes G, Hus V, Igliozzi R, Kim C, Klauck SM, Kolevzon A, Korvatska O, Kustanovich V, Lajonchere CM, Lamb JA, Laskawiec M, Leboyer M, Le Couteur A, Leventhal BL, Lionel AC, Liu XQ, Lord C, Lotspeich L, Lund SC, Maestrini E,
Mahoney W, Mantoulan C, Marshall CR, McConachie H, McDougle CJ, McGrath J, McMahon WM, Melhem NM, Merikangas A, Migita O, Minshew NJ, Mirza GK, Munson J, Nelson SF, Noakes C, Noor A, Nygren G, Oliveira G, Papanikolaou K, Parr JR, Parrini B, Paton T, Pickles A, Piven J, Posey DJ, Poustka A, Poustka F, Prasad A, Ragoussis J, Renshaw K, Rickaby J, Roberts W, Roeder K, Roge B, Rutter ML, Bierut LJ, Rice JP, Salt J, Sansom K, Sato D, Segurado R, Senman L, Shah N, Sheffield VC, Soorya L, Sousa I, Stoppioni V, Strawbridge $C$, Tancredi R, Tansey $K$, Thiruvahindrapduram B, Thompson AP, Thomson $\mathrm{S}$, Tryfon A, Tsiantis J, Van Engeland H, Vincent JB, Volkmar F, Wallace S, Wang K, Wang Z, Wassink TH, Wing K, Wittemeyer K, Wood S, Yaspan BL, Zurawiecki D, Zwaigenbaum L, Betancur C, Buxbaum JD, Cantor RM, Cook EH, Coon H, Cuccaro ML, Gallagher L, Geschwind DH, Gill M, Haines JL, Miller J, Monaco AP, Nurnberger Jr. JI, Paterson AD, Pericak-Vance MA, Schellenberg GD, Scherer SW, Sutcliffe JS, Szatmari P, Vicente AM, Vieland VJ, Wijsman EM, Devlin B, Ennis S, Hallmayer J (2010). A genome-wide scan for common alleles affecting risk for autism. Human Molecular Genetics 19, 4072-4082.

Baron-Cohen S, Wheelwright S, Skinner R, Martin J, Clubley E (2001). The Autism-Spectrum Quotient (AQ) : evidence from Asperger syndrome/high-functioning autism, males and females, scientists and mathematicians. Journal of Autism and Developmental Disorders 31, 5-17.

Biederman J, Faraone SV, Monuteaux MC, Bober M, Cadogen E (2004). Gender effects on attention-deficit/ hyperactivity disorder in adults, revisited. Biological Psychiatry 55, 692-700.

Boomsma D, Busjahn A, Peltonen L (2002). Classical twin studies and beyond. Nature Review Genetics 3, 872-882.

Boomsma DI, Saviouk V, Hottenga JJ, Distel MA, de Moor MH, Vink JM, Geels LM, van Beek JH, Bartels M, de Geus EJ, Willemsen G (2010). Genetic epidemiology of attention deficit hyperactivity disorder (ADHD index) in adults. PLOS ONE 5, e10621.

Brugha TS, McManus S, Bankart J, Scott F, Purdon S, Smith J, Bebbington P, Jenkins R, Meltzer H (2011). Epidemiology of autism spectrum disorders in adults in the community in England. Archives of General Psychiatry 68, 459-465.

Conners CK, Erhardt D, Sparrow E (1999). Conners' Adult ADHD Rating Scales. Multi-Health Systems: North Tonawanda, NY.

Constantino JN, Todd RD (2003). Autistic traits in the general population: a twin study. Archives of General Psychiatry 60, 524-530.

Cools R, D'Esposito M (2011). Inverted U-shaped dopamine actions on human working memory and cognitive control. Biological Psychiatry 69, e113-e125.

Cortina JM (1993). What is coefficient alpha? An examination of theory and applications. Journal of Applied Psychology 78, 98-104.

Cramer AO, Waldorp LJ, van der Maas HL, Borsboom D (2010). Comorbidity: a network perspective. Behavioral and Brain Sciences 33, 137-150; discussion 150-193. 
Diamond A (2011). Biological and social influences on cognitive control processes dependent on prefrontal cortex. Progress in Brain Research 189, 319-339.

Elia J, Gai X, Xie HM, Perin JC, Geiger E, Glessner JT, D'Arcy M, deBerardinis R, Frackelton E, Kim C, Lantieri F, Muganga BM, Wang L, Takeda T, Rappaport EF, Grant SF, Berrettini W, Devoto M, Shaikh TH, Hakonarson H, White PS (2011). Rare structural variants found in attention-deficit hyperactivity disorder are preferentially associated with neurodevelopmental genes. Molecular Psychiatry 15, 637-646.

Franke B, Faraone SV, Asherson P, Buitelaar J, Bau CH, Ramos-Quiroga JA, Mick E, Grevet EH, Johansson S, Haavik J, Lesch KP, Cormand B, Reif A (2012). The genetics of attention deficit/hyperactivity disorder in adults, a review. Molecular Psychiatry 17, 960-987.

Happe F, Ronald A (2008). The 'fractionable autism triad': a review of evidence from behavioural, genetic, cognitive and neural research. Neuropsychology Review 18, 287-304.

Hoekstra RA, Bartels M, Verweij CJ, Boomsma DI (2007). Heritability of autistic traits in the general population. Archives of Pediatrics and Adolescent Medicine 161, 372-377.

Hoekstra RA, Vinkhuyzen AA, Wheelwright S, Bartels M, Boomsma DI, Baron-Cohen S, Posthuma D, van der Sluis S (2011). The construction and validation of an abridged version of the Autism-Spectrum Quotient (AQ-Short). Journal of Autism and Developmental Disorders 41, 589-596.

Hofvander B, Delorme R, Chaste P, Nyden A, Wentz E, Stahlberg O, Herbrecht E, Stopin A, Anckarsater H, Gillberg C, Rastam M, Leboyer M (2009). Psychiatric and psychosocial problems in adults with normal-intelligence autism spectrum disorders. BMC Psychiatry 9, 35.

Kessler RC, Green JG, Adler LA, Barkley RA, Chatterji S, Faraone SV, Finkelman M, Greenhill LL, Gruber MJ, Jewell M, Russo LJ, Sampson NA, Van Brunt DL (2010). Structure and diagnosis of adult attention-deficit/ hyperactivity disorder: analysis of expanded symptom criteria from the Adult ADHD Clinical Diagnostic Scale. Archives of General Psychiatry 67, 1168-1178.

Larsson H, Anckarsater H, Rastam M, Chang Z, Lichtenstein P (2012). Childhood attention-deficit hyperactivity disorder as an extreme of a continuous trait: a quantitative genetic study of 8,500 twin pairs. Journal of Child Psychology and Psychiatry 53, 73-80.

Levy D, Ronemus M, Yamrom B, Lee YH, Leotta A, Kendall J, Marks S, Lakshmi B, Pai D, Ye K, Buja A, Krieger A, Yoon S, Troge J, Rodgers L, Iossifov I, Wigler M (2011). Rare de novo and transmitted copy-number variation in autistic spectrum disorders. Neuron 70, 886-897.

Lichtenstein P, Carlstrom E, Rastam M, Gillberg C, Anckarsater H (2010). The genetics of autism spectrum disorders and related neuropsychiatric disorders in childhood. American Journal of Psychiatry 167, 1357-1363.

Lundstrom S, Chang Z, Kerekes N, Gumpert CH, Rastam M, Gillberg C, Lichtenstein P, Anckarsater H (2011). Autistic-like traits and their association with mental health problems in two nationwide twin cohorts of children and adults. Psychological Medicine 41, 2423-2433.

Lundstrom S, Chang Z, Rastam M, Gillberg C, Larsson H, Anckarsater H, Lichtenstein P (2012). Autism spectrum disorders and autistic-like traits: similar etiology in the extreme end and the normal variation. Archives of General Psychiatry 69, 46-52.

Neale BM, Medland S, Ripke S, Anney RJ, Asherson P, Buitelaar J, Franke B, Gill M, Kent L, Holmans P, Middleton F, Thapar A, Lesch KP, Faraone SV, Daly M, Nguyen TT, Schafer H, Steinhausen HC, Reif A, Renner TJ, Romanos M, Romanos J, Warnke A, Walitza S, Freitag C, Meyer J, Palmason H, Rothenberger A, Hawi Z, Sergeant J, Roeyers H, Mick E, Biederman J (2010). Case-control genome-wide association study of attentiondeficit/hyperactivity disorder. Journal of the American Academy of Child and Adolescent Psychiatry 49, 906-920.

Neale MC, Boker SM, Xie G, Maes HHM (2006). Mx: Statistical Modeling. Department of Psychiatry, Virginia Commonwealth University: Richmond, VA.

Neale MC, Kendler KS (1995). Models of comorbidity for multifactorial disorders. American Journal of Human Genetics 57, 935-953.

Nikolas MA, Burt SA (2010). Genetic and environmental influences on ADHD symptom dimensions of inattention and hyperactivity: a meta-analysis. Journal of Abnormal Psychology 119, 1-17.

Pinto D, Pagnamenta AT, Klei L, Anney R, Merico D, Regan R, Conroy J, Magalhaes TR, Correia C, Abrahams BS, Almeida J, Bacchelli E, Bader GD, Bailey AJ, Baird G, Battaglia A, Berney T, Bolshakova N, Bolte S, Bolton PF, Bourgeron T, Brennan S, Brian J, Bryson SE, Carson AR, Casallo G, Casey J, Chung BH, Cochrane L, Corsello C, Crawford EL, Crossett A, Cytrynbaum C, Dawson G, de Jonge M, Delorme R, Drmic I, Duketis E, Duque F, Estes A, Farrar P, Fernandez BA, Folstein SE, Fombonne E, Freitag CM, Gilbert J, Gillberg C, Glessner JT, Goldberg J, Green A, Green J, Guter SJ, Hakonarson H, Heron EA, Hill M, Holt R, Howe JL, Hughes G, Hus V, Igliozzi R, Kim C, Klauck SM, Kolevzon A, Korvatska O, Kustanovich V, Lajonchere CM, Lamb JA, Laskawiec M, Leboyer M, Le Couteur A, Leventhal BL, Lionel AC, Liu XQ, Lord C, Lotspeich L, Lund SC, Maestrini E, Mahoney W, Mantoulan C, Marshall CR, McConachie H, McDougle CJ, McGrath J, McMahon WM, Merikangas A, Migita O, Minshew NJ, Mirza GK, Munson J, Nelson SF, Noakes C, Noor A, Nygren G, Oliveira G, Papanikolaou K, Parr JR, Parrini B, Paton T, Pickles A, Pilorge M, Piven J, Ponting CP, Posey DJ, Poustka A, Poustka F, Prasad A, Ragoussis J, Renshaw K, Rickaby J, Roberts W, Roeder K, Roge B, Rutter ML, Bierut LJ, Rice JP, Salt J, Sansom K, Sato D, Segurado R, Sequeira AF, Senman L, Shah N, Sheffield VC, Soorya L, Sousa I, Stein O, Sykes N, Stoppioni V, Strawbridge C, Tancredi R, Tansey K, Thiruvahindrapduram B, Thompson AP, Thomson $S$, Tryfon A, Tsiantis J, Van Engeland H, Vincent JB, Volkmar F, Wallace S, Wang K, Wang Z, Wassink TH, Webber C, Weksberg R, Wing K, Wittemeyer K, Wood S, Wu J, Yaspan BL, Zurawiecki D, Zwaigenbaum $L$, Buxbaum JD, Cantor RM, Cook EH, Coon H, Cuccaro ML, Devlin B, Ennis S, Gallagher L, Geschwind DH, Gill M, Haines JL, Hallmayer J, Miller J, Monaco AP, Nurnberger Jr. JI, Paterson AD, Pericak-Vance MA, Schellenberg GD, Szatmari P, Vicente AM, Vieland VJ, 
Wijsman EM, Scherer SW, Sutcliffe JS, Betancur C (2010). Functional impact of global rare copy number variation in autism spectrum disorders. Nature 466, 368-372.

Polderman TJ, Derks EM, Hudziak JJ, Verhulst FC, Posthuma D, Boomsma DI (2007). Across the continuum of attention skills: a twin study of the SWAN ADHD rating scale. Journal of Child Psychology and Psychiatry 48, 1080-1087.

Polderman TJC, Stins JF, Posthuma D, Gosso MF, Verhulst FC, Boomsma DI (2006). The phenotypic and genotypic relation between working memory speed and capacity. Intelligence 34, 549-560.

Posthuma D, Boomsma DI (2000). A note on the statistical power in extended twin designs. Behavior Genetics 30, 147-158.

Reiersen AM, Constantino JN, Grimmer M, Martin NG, Todd RD (2008). Evidence for shared genetic influences on self-reported ADHD and autistic symptoms in young adult Australian twins. Twin Research and Human Genetics 11, 579-585.

Rijsdijk F (2007). Introduction to statistics. In Statistical Genetics: Gene Mapping Through Linkage and Association (ed. M. Ferreira, B. Neale, S. Medland and D. Posthuma), pp. 43-59. Taylor \& Francis: London.

Riso LP, Klein DN, Ferro T, Kasch KL, Pepper CM, Schwartz JE, Aronson TA (1996). Understanding the comorbidity between early-onset dysthymia and cluster B personality disorders: a family study. American Journal of Psychiatry 153, 900-906.

Robinson EB, Koenen KC, McCormick MC, Munir K, Hallett V, Happe F, Plomin R, Ronald A (2011). Evidence that autistic traits show the same etiology in the general population and at the quantitative extremes $(5 \%, 2.5 \%$, and 1\%). Archives of General Psychiatry 68, 1113-1121.

Rommelse NN, Geurts HM, Franke B, Buitelaar JK, Hartman CA (2011). A review on cognitive and brain endophenotypes that may be common in autism spectrum disorder and attention-deficit/hyperactivity disorder and facilitate the search for pleiotropic genes. Neuroscience and Biobehavioral Reviews 35, 1363-1396.

Ronald A, Edelson LR, Asherson P, Saudino KJ (2010). Exploring the relationship between autistic-like traits and ADHD behaviors in early childhood: findings from a community twin study of 2-year-olds. Journal of Abnormal Child Psychology 38, 185-196.

Ronald A, Hoekstra RA (2011). Autism spectrum disorders and autistic traits: a decade of new twin studies. American Journal of Medical Genetics. Part B, Neuropsychiatric Genetics 156B, 255-274.

Ronald A, Simonoff E, Kuntsi J, Asherson P, Plomin R (2008). Evidence for overlapping genetic influences on autistic and ADHD behaviours in a community twin sample. Journal of Child Psychology and Psychiatry 49 535-542.

Simon V, Czobor P, Balint S, Meszaros A, Bitter I (2009).

Prevalence and correlates of adult attention-deficit hyperactivity disorder: meta-analysis. British Journal of Psychiatry 194, 204-211.

Stahlberg O, Soderstrom H, Rastam M, Gillberg C (2004). Bipolar disorder, schizophrenia, and other psychotic disorders in adults with childhood onset AD/HD and/or autism spectrum disorders. Journal of Neural Transmission 111, 891-902.

Taurines R, Schwenck C, Westerwald E, Sachse M, Siniatchkin M, Freitag C (2012). ADHD and autism: differential diagnosis or overlapping traits? A selective review. Attention Deficit and Hyperactivity Disorders 4, 115-139.

van den Berg SM, Willemsen G, de Geus EJ, Boomsma DI (2006). Genetic etiology of stability of attention problems in young adulthood. American Journal of Medical Genetics. Part B, Neuropsychiatric Genetics 141B, 55-60.

van der Sluis S, Willemsen G, de Geus EJ, Boomsma DI, Posthuma D (2008). Gene-environment interaction in adults' IQ scores: measures of past and present environment. Behavior Genetics 38, 348-360.

Vinkhuyzen AAE, van der Sluis S, de Geus EJC, Boomsma DI, Posthuma D (2010). Genetic influences on 'environmental' factors. Genes, Brain and Behavior $\mathbf{9}$, 276-287.

Visscher PM, Brown MA, McCarthy MI, Yang J (2012). Five years of GWAS discovery. American Journal of Human Genetics 90, 7-24.

Williams NM, Franke B, Mick E, Anney RJ, Freitag CM, Gill M, Thapar A, O'Donovan MC, Owen MJ, Holmans P, Kent L, Middleton F, Zhang-James Y, Liu L, Meyer J, Nguyen TT, Romanos J, Romanos M, Seitz C, Renner TJ, Walitza S, Warnke A, Palmason H, Buitelaar J, Rommelse N, Vasquez AA, Hawi Z, Langley $K$, Sergeant J, Steinhausen HC, Roeyers H, Biederman J, Zaharieva I, Hakonarson H, Elia J, Lionel AC, Crosbie J, Marshall CR, Schachar R, Scherer SW, Todorov A, Smalley SL, Loo S, Nelson S, Shtir C, Asherson P, Reif A, Lesch KP, Faraone SV (2012). Genome-wide analysis of copy number variants in attention deficit hyperactivity disorder: the role of rare variants and duplications at 15q13.3. American Journal of Psychiatry 169, 195-204. Williams NM, Zaharieva I, Martin A, Langley K, Mantripragada K, Fossdal R, Stefansson H, Stefansson K, Magnusson P, Gudmundsson OO, Gustafsson O, Holmans P, Owen MJ, O'Donovan M, Thapar A (2010). Rare chromosomal deletions and duplications in attention-deficit hyperactivity disorder: a genome-wide analysis. Lancet 376, 1401-1408. 